\title{
Influence of Water Stress on the Citric Acid Metabolism Related Gene Expression in the Ponkan Fruits
}

\author{
Guifu Zhang1,2, Shenxi Xie ${ }^{1}$ \\ ${ }^{1}$ Horticulture \& Landscape College, Hunan Agricultural University, Hunan, China \\ ${ }^{2}$ Nuclear Technology and Chemical \& Biological College, Hubei University of Science and Engineering, Hubei, China \\ Email: ShenxiXie@163.com
}

Received 6 November 2014; revised 27 November 2014; accepted 1 December 2014

Copyright (C) 2014 by authors and Scientific Research Publishing Inc.

This work is licensed under the Creative Commons Attribution International License (CC BY). http://creativecommons.org/licenses/by/4.0/

(c) (i) Open Access

\section{Abstract}

To explore the influence of water stress on fruit quality and gene expression related to citrate metabolism of ponkan. The test were conducted from May 15 to December 24 in 2013 using six-year-old ponkan (C. blanco $\mathrm{cv}$. Ponkan) trees with $40 \%$ soil water conditions by taken regular watering as control. The content of acids in fruit were determined by HPLC, and relative expression of related genes of citric acid metabolic were determined by relative fluorescence quantitative PCR. The results showed that the content of citric acid, malic acid, quinic acid and total organic acids per gram sarcocarp were extremely increased by $285.2 \%, 320 \%, 480 \%$ and $299.1 \%$, and the content of per-fruit organic acid were $77.39 \%, 89.64 \%, 117.24 \%$ and $75.9 \%$ respectively compared to those control in the fruit mature stage. Relative expression of CitCS1, CitCS2 were higher than control, and relative expression of CitAco1, CitAco2, CitAco3 had a certain increase in the late fruit development, were lower in mature stage. Three relative expression of CitIDH gene were higher than control in mature stage. Low CitGAD4 relative expression and undetectable in mature stage, the relative expression of CitGAD5 gene had a role in promoting under water stress. Furthermore, the relative expression of CitCS1, CitCS2, CitACO1, CitACO3, CitIDH1, CitIDH2, CitIDH3, CitGAD4 and CitGAD5 were influenced by water stress through the correlation analysis. Water stress caused the accumulation of citric acid, declined fruit quality, leaded to change of the genetic relative expression about citric acid synthesis and degradation. The down-regulation of CitACO1, CitGAD4 and up-regulation of CitCS1, CitCS2 might be one of the reasons that promoted to the accumulation of citric acid.

\section{Keywords}

Ponkan, Water Stress, Fruit, Quality, Citric Acid, Gene Expression 


\section{Introduction}

Ponkan (Citrus reticulata blanco cv. Ponkan) is the second most productive citrus species in China [1]. Ponkan is primarily grown in the south, where the land is characterized by hills, making planting and irrigation conditions are poor. Seasonal aridity during the summer and fall often coincides with the crucial fruit swelling stage, which is mainly marked as the elevation of soluble solids and acidity [2]. The organic acid content, comprised mainly of citric acid, malic acid, tartaric, and quinic acid, is one of the major parameters in determining fruit quality. Most citrus fruits belong to the citric acid type [3]. The citric acid is distributed throughout the juice sac of the fruit, and makes up 75\% - 88\% of the organic acid found in mature fruits [4]. Malic and quinic acids are the major organic acids found in the white cortex and the epicarp [5].

Citric acid metabolism is a major step in the organic acid accumulation in citrus fruits. The synthetic pathway is mainly composed of the tricarboxylic acid cycle (TCA) cycle, while the degradation primarily occurs through the $\gamma$-Aminobutyricacid (GABA) and Glutamine Synthetase (GS) pathways. Citrate Synthase (CS; EC 2.3.3.1), cis-aconitase (Aco; EC 4.2.1.3), isocitrate dehydrogenase (IDH; EC 1.1.1.42), and glutamate decarboxylase (GAD; EC 4.1.1.15), are among many of the enzymes involved in these pathways [6] [7]. Current research on citrus water stress focuses on morphological, physiological, chemical, and roughly qualitative aspects [8]-[11], instead of on the citric acid metabolism. Naturally grown Ponkan was put under water stress in order to investigate the changes in gene expression related to the organic acid content and citric acid metabolism, explored the reasons about the increase of organic acid under water stress, attempting to provide theoretical reference for fighting drought and improving the quality.

\section{Materials and Methods}

\subsection{Materials}

Sexennial C. blanco cv. Ponkan were grown in pots in a greenhouse at the National Citrus improvement center in Hunan Agricultural University. The center made the potted soil using the garden soil, rotteh organic fertilizer, fine sand and plant ash in a 1:1:0.8:0.2 ratio.

\subsection{Methods}

The experiments were conducted at the National Citrus improvement center in Changsha branch from MarchDecember, 2013. Our preliminary experiments indicated that Ponkan in soils with 20\% of maximal water capacity do not grow and develop, while $60 \%$ water stress had no obvious influences on development. Therefore, we decided to use a soil with $40 \%$ maximal water capacity as the water stress input in our model, while using normal irrigation (the water content was higher than $60 \%$ of the maximal soil water capacity) as the control (we watered the soils every two days until they were at their maximal water capacity). Each processing repeats 5 times. We began managing all the experimental conditions since March. On May 25th, we selected Ponkan trees with similar growth potentials to be used in the treatments after the fruit naturally dropped from the trees. In order to maintain the water content within designed range, we measured the soil water concentration using a Spectrum Field Scout TDR 300 type (Spectrum Technologies, Inc., Plainifield, IL, USA) soil-moisture content analyzer at 9:00 and 18:00 hours every day. Each time we randomly chose 5 points to measure and averaged them, then supplied the lost water. For each treatment, we took samples 27, 54 (the stage of fruit cell division), 81, 108 (the stage of fruit cell expansion), 135, 162, 189 (the fruit mature period) days after the initial treatments. Each point had 3 repeats. We stored half of the samples at $-40^{\circ} \mathrm{C}$ for measuring the organic acids; the remaining samples were snap-frozen in liquid nitrogen and kept at $-80^{\circ} \mathrm{C}$ for citric acid metabolism related gene expression analysis.

The organic acid content of the Ponkan fruit flesh was measured using HPLC (SHIMADZU LC—20AT high performance liquid chromatograph), as described by Hai Bo Wang, et al. [12]. The acid components were calculated using a N2000 chromatographic work station (Ver: 3.30).

The total RNA content of the fruit flesh was extracted as described in TransZol Plant kit (Transgene BioTech, Beijing, China). We used iScript cDNA Synthesis Kit (Bio-Rad, USA) to synthesize a single strand cDNA for RT-PCR analysis.

We used Bio-Rad fluorescence Q-PCR machine (CFX 96 real-time PCR detection system, USA) and SsoFast EvaGreen Supermix kit from Bio-Rad to conduct Q-PCR gene expression analysis. The Actin gene as the inter- 
nal control, and we obtained the gene sequences from the published Clementine Citrus haploid genome

(www.phytozome.net/clementine). The primers were designed according to the instruction of Primer Express Version 3.0 and synthesized by Sangon Biotech (Shanghai). All PCR primers are shown in Table 1.

The reaction system was $10 \mu \mathrm{L}$, containing $\mathrm{ddH}_{2} \mathrm{O} 3.6 \mu \mathrm{L}$, forward and reverse primers each $0.4 \mu \mathrm{L}, 25 \mathrm{ng} / \mu \mathrm{L}$ template $0.6 \mu \mathrm{L}$, and $2 \times$ Super Mix polymerase $5 \mu \mathrm{L}$ (Bio-Rad). The reaction program was as follows: $95^{\circ} \mathrm{C}$ predenaturing $30 \mathrm{~s} ; 40$ cycles of $95^{\circ} \mathrm{C} 5 \mathrm{~s} ; 60^{\circ} \mathrm{C} 10 \mathrm{~s} ; 72^{\circ} \mathrm{C} 15 \mathrm{~s}$. The dissolving curve was as follows: $50^{\circ} \mathrm{C}$ incubation $1 \mathrm{~min}, 95^{\circ} \mathrm{C}$ incubation $1 \mathrm{~min}$.

The experiments were randomly designed, Using Excel 2003 drawing and the Duncan tests in the SPSS17.0 was used to significant LSD test $(\mathrm{p}<0.05)$.

\section{Results and Discussion}

\subsection{The Influence of Water Stress on the Organic Acid Content in Fruits and Pulp of Ponkan}

From Figure 1 we can find that citric acid is was found to be the major organic acid in Ponkan fruits, which accountings for $91.82 \%$ of the total content in single fruit (Figure 1). Under the condition of water stress, the quinic acid and malic acid concentrations (acid content per gram flesh) showed a changing trend of showed an initial increase, then subsequent decrease during Ponkan fruit development, reach their maximal concentrations at Day 81. Citric acid and total acid concentrations showed the similar trend, early rising gradually, reach maximum at Day 162, concentrations decrease in fruit ripening. In the control, the quinic acid, malic acid, citric acid and total acid concentrations are showed an initial increase after the drop trend. The malic acid reached its maximal concentration on Day 54, but the quinic acid, citric acid and total acid contents did not reach their maximal concentrations until Day 81 . Therefore, $40 \%$ water stress leads to citric acid accumulation, and an elevation of total organic acid in the fruits. The citric acid, malic acid, quinic acid, and total organic acid contents in $189 \mathrm{~d}$ matured fruits increased by $285.2 \%, 320 \%, 480 \%$ and $299.1 \%$, respectively, compared with the control group.

The error bars means standard error (SE) of three biological replicates, Different letters on the adjacent columns mean significant difference $(\mathrm{p}<0.05)$. The same is as below.

The citric acid and total acid content in the pulp showed the similar increasing trends in the early stages of development under $40 \%$ water stress, reaching the peak at Day 108 , and did not change during the later stages in the control test (Figure 2). The citric and total acid contents were lower than the controls in every stage. The quinic acid content in the pulp reached the maximal value on Day 81, created a small peak at Day 135, and then gradually decreased, When compared with the control group, the quinic acid reduce. The malic acid content in the pulp also showed a double-peak trend. It was lower than the control group throughout the experiment except on Day 135. When the fruits matured on Day 189, the contents of quinic acid, malic acid, citric acid and total acid are $117.24 \%, 89.64 \%, 77.39 \%$ and $75.9 \%$ of the control group, respectively.

Table 1. Primer sequences of real-time quantitative PCR.

\begin{tabular}{ccc}
\hline Gene & Forward primer (5' to $3^{\prime}$ ) & Reverse primer (3' to 5') \\
\hline CitCS1 & CGAGGCCATTTGATTACTGC & TGTTGGCCATTTTGTAACCA \\
CitCS2 & GGCCTCTGGTTTTCTGTTTG & ACAATACCACGCAGGGAAAG \\
CitACO1 & CCAACTGGTGCTCTTCAACC & TGTCTAGGGCGTGTCCTATTG \\
CitACO2 & CTAGGCGGACTTGCTTCATC & CCTTTTGAATTGTTCCCAGAA \\
CitIDH1 & GCATGAGGCATGAGGATTC & TTGGCCAAAAGAAAAATGAA \\
CitIDH2 & GAAAATTGGGGATTGGGATT & CAACAGAGGTGCAGCTCAAA \\
CitIDH3 & GCTTGGACATTTCGTTGGTT & TCTTGTTCCATGAAAGGGTTG \\
CitGAD4 & TGTTTTTCTTTGAGGGGAATG & GGAATTTCACAGGCAGCAAG \\
CitGAD5 & CGTCTCCGAAAGGAAAGCTA & AAATAATCAAAATCGTCAACATGC \\
Actin & GGTTCCAAACATAAGACGAGACA & CACTTCATAAGCGTGCAAGAA \\
\hline
\end{tabular}



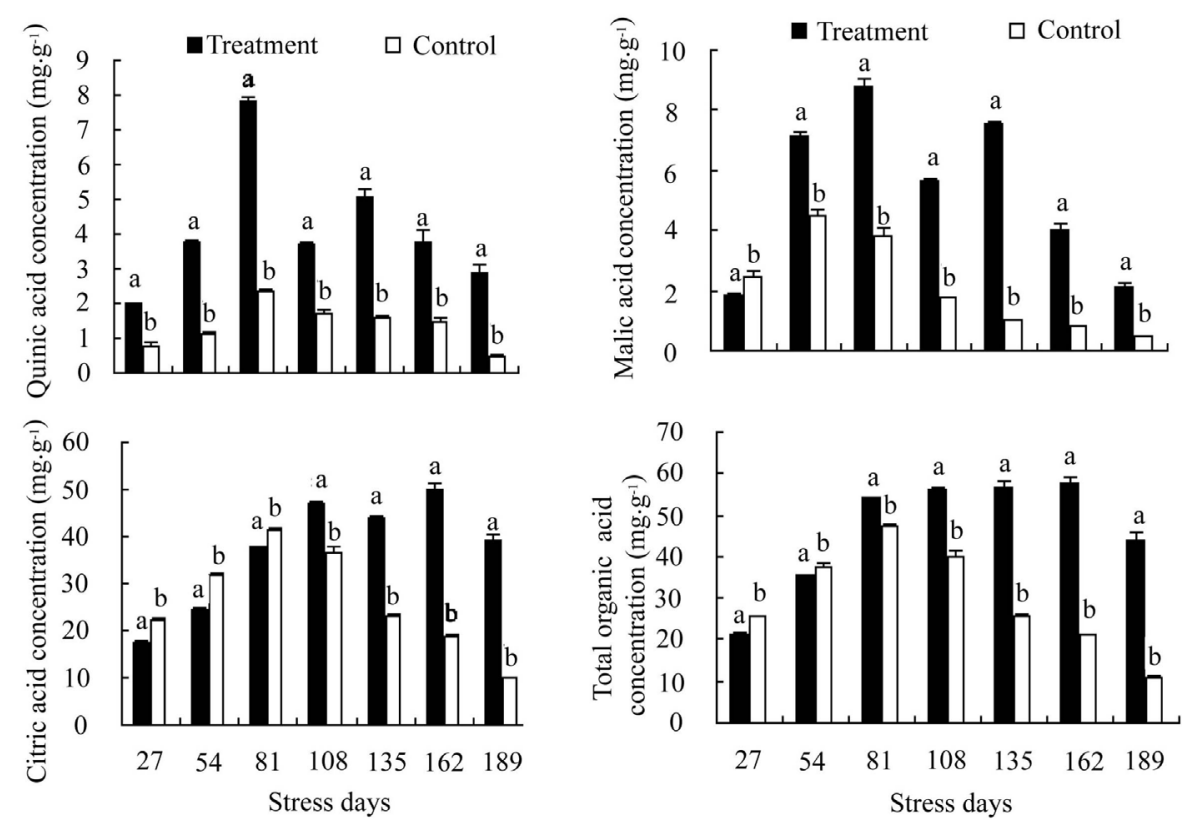

Figure 1. The influence of water stress on the organic acid concentrations in Ponkan friuts.
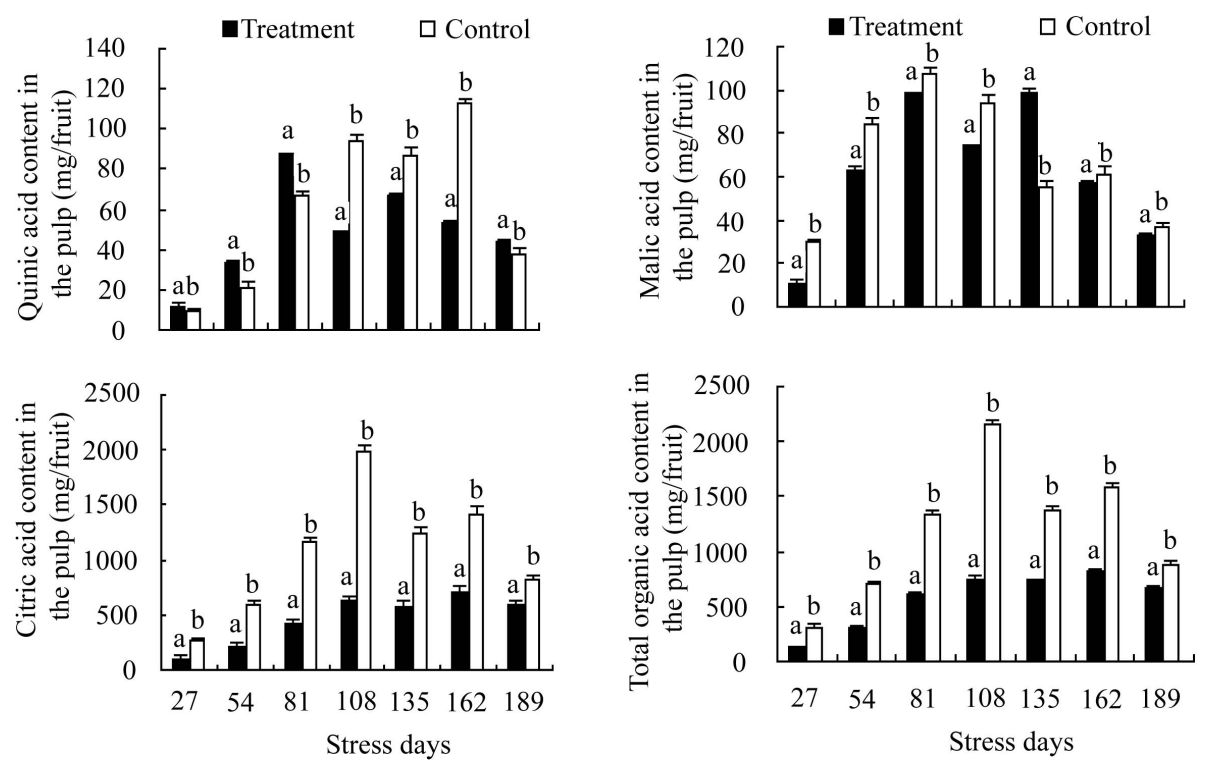

Figure 2. The influence of water stress on the acid content in the Ponkan pulp.

\subsection{The Influence of Water Stress on Citric Acid Metabolism Related Genes in Ponkan Fruits}

\subsubsection{The Influence on the CitCSs Expression in the Fruits}

Two CS genes were isolated in the Ponkan genome and named CitCS1 and CitCS2. With the ongoing water stress and fruit development, the relative expression of CitCS1 showed an increasing trend and was significantly higher than the control group, reaching a maximum on Day 162, which was 2.74 times that of the control group. On Day 189, there were no statistical differences between the experimental and control group. The expression of CitCS2 was significantly higher than the control group throughout development, reaching the maximum on Day 189, which was 1.64 times higher than that of the control group. In summary, the relative expressions of CitCS1 and CitCS2 were significant higher than the control group throughout development (Figure 3). 

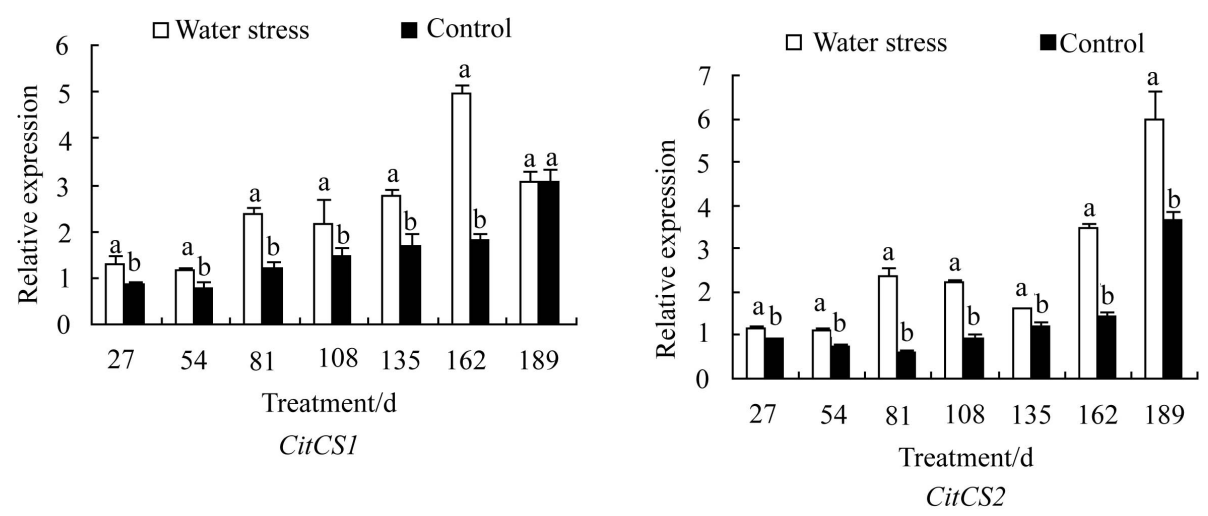

Figure 3. Different treatments on the relative expressions of CitCSs gene family members in Ponkan fruits.

\subsubsection{The Influence on the Fruit CitAcos Expression}

Aco-catalyzed citric acid to isocitric acid reaction is the first step of citric acid degradation in citrus fruits. The citrus Aco gene has three family members. During the ongoing fruit development and water stress, CitAcos have different expression patterns. As shown in Figure 4, CitAco1 showed a trend of decreasing, then increasing, and then decreasing again (Figure 4). Before Day 108, it was significantly higher than the control group, and it was 1.67 times higher than the control group on Day 162. However on Day 189, it was significantly lower at only 7\% of the control group. The relative expression of CitAco2 was the lowest among Aco gene family. In most stages of the treatment, it was significantly higher than the control group, while on Day 108 and Day 189 it was lower, at only $43.5 \%$ and $78.8 \%$ of the control group, respectively. The relative expression of CitAco3 did not significantly increase in the early and middle stages with a fluctuation when compared with the control group. However, in the late stage of the fruit development, CitAco3 expression increased to a level 8.3 times that of the control group. During the fruit maturation stage, CitAco3 expression reduced to $69.23 \%$ of the control group.

\subsubsection{The Influence on Fruit CitIDHs Expression}

The transformation of IDH-catalyzed isocitric acid to $\alpha$-ketoglutaric acid is the second step in the citric acid degradation in citrus fruits. The citrus IDH gene also has 3 family members. Under $40 \%$ water stress, relative expression of the three CitIDH genes was different during the development of citrus fruit (Figure 5). The relative expression of CitIDH1 was low in the early stage, significantly lower than the control group in the middle stage, and significantly higher than the control group in the late stage (1.96 times of the control group). The relative expression of CitIDH2 showed an increasing trend, which was always significantly higher than the control group. On Day 162 and Day 189, the CitIDH2 was 2.17 and 3.8 times of the control group, respectively, which was especially high. The relative expression of CitIDH3 showed a trend similar to that of the control group. It was stable at the early stage of fruit development, increased dramatically in the middle stage and decreased again in the late stage. Compared with the control group, CitIDH3 in the water stress group was significantly higher during the early stage, lower in the middle stage, and significantly lower in the late stage. CitIDH3 expression was significantly higher in the maturation stage, which was 2.57 times of the control group.

\subsection{Correlation between the Citric Acid Metabolic Genes and Citric Acid Content in the Ponkan Fruits}

As shown in Table 2, in the 10 genes involved in the Ponkan fruits' citric acid metabolism, when looking at gene expressions, CitGAD4 is highly correlated, CitCS1 and CitAco1 are significantly correlated, CitCS2 and CitGAD5 are commonly correlated, while others are low-commonly correlated with the citric acid content. Under $40 \%$ water stress, when looking at the gene expressions, CitCS1 is highly correlated, CitCS2, CitAco3, CitIDH2 and CitGAD5 are significantly correlated, CitAco1, CitIDH1 and CitIDH3 are commonly correlated, while the other two genes are low-commonly correlated with the citric acid content. These results indicate that $40 \%$ water stress is able to influence the relative gene expressions of the citric acid metabolism related genes in Ponkan fruits. This influence will lead to increased expressions of CitCS1, CitCS2, and reduced expressions of 

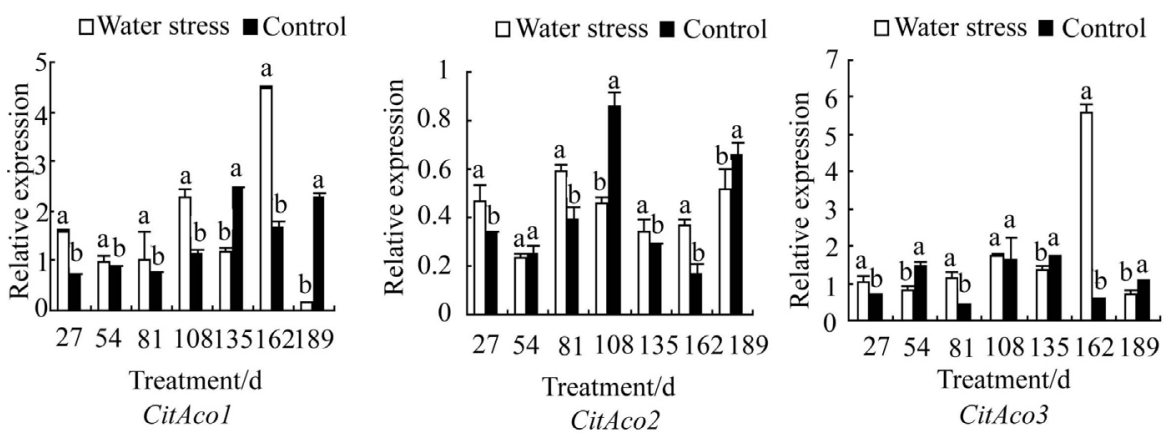

Figure 4. Relative gene expression of the CitAcos gene family in Ponkan fruits with different treatments.
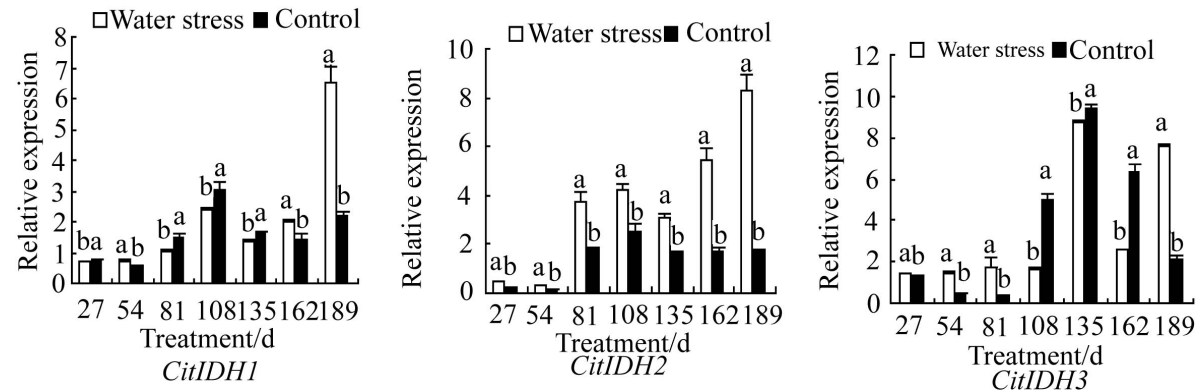

Figure 5. The influence on CitIDHs gene family members in Ponkan fruits with different treatments.

Table 2. The correlation of of the relative expression of related genes about citric acid metabolism and citric acid content.

\begin{tabular}{|c|c|c|c|}
\hline Genetic types & Treatment & Equations of orrelation & Correlation index \\
\hline \multirow{2}{*}{ CitCS1 } & Water stress & $Y=0.4743 X+0.6343$ & $r=0.797$ \\
\hline & Control & $Y=0.3239 X+0.2614$ & $r=0.524$ \\
\hline \multirow{2}{*}{ CitCS2 } & Water stress & $Y=0.66 X-0.0786$ & $r=0.681$ \\
\hline & Control & $Y=0.3668 X-0.1214$ & $r=0.429$ \\
\hline \multirow{2}{*}{ CitACO1 } & Water stress & $Y=0.1043 X+1.2529$ & $r=-0.463$ \\
\hline & Control & $Y=0.2882 X+0.2471$ & $\mathrm{r}=-0.689$ \\
\hline \multirow{2}{*}{ CitACO2 } & Water stress & $\mathrm{Y}=0.0064 \mathrm{X}+0.4$ & $r=0.103$ \\
\hline & Control & $\mathrm{Y}=0.0257 \mathrm{X}+0.3171$ & $r=0.124$ \\
\hline \multirow{2}{*}{ CitACO3 } & Water stress & $\mathrm{Y}=0.3139 \mathrm{X}+0.5157$ & $r=-0.567$ \\
\hline & Control & $Y=0.025 X+0.9729$ & $r=0.056$ \\
\hline \multirow{2}{*}{ CitIDH1 } & Water stress & $Y=0.7275 X-0.8157$ & $r=0.334$ \\
\hline & Control & $\mathrm{Y}=0.2207 \mathrm{X}+0.7029$ & $r=0.053$ \\
\hline \multirow{2}{*}{ CitIDH2 } & Water stress & $Y=0.1786 X-1.0729$ & $r=-0.681$ \\
\hline & Control & $Y=0.2661 X+0.3357$ & $r=0.136$ \\
\hline \multirow{2}{*}{ CitIDH3 } & Water stress & $\mathrm{Y}=0.9932 \mathrm{X}-0.37$ & $\mathrm{r}=-0.351$ \\
\hline & Control & $Y=0.8371 X+0.2229$ & $\mathrm{r}=-0.263$ \\
\hline \multirow{2}{*}{ CitGAD4 } & Water stress & $Y=-0.0568 X+0.6514$ & $r=-0.218$ \\
\hline & Control & $Y=0.5393 X-0.4043$ & $\mathrm{r}=-0.711$ \\
\hline \multirow{2}{*}{ CitGAD5 } & Water stress & $\mathrm{Y}=0.5471 \mathrm{X}+0.43$ & $\mathrm{r}=-0.546$ \\
\hline & Control & $Y=0.22 X+0.7443$ & $\mathrm{r}=-0.383$ \\
\hline
\end{tabular}


CitAco1, CitGAD4. The relative expressions of CitAco3, CitIDH1, CitIDH2, CitIDH3, CitGAD5 also increase.

\section{Discussions}

\subsection{The Influence of Water Stress on the Organic Acid Content in Fruits and Pulp of Ponkan}

Generally, it is thought that the organic acid content will decrease in the late stage of fruit maturation [13]. We compared the concentration and total content of organic acid in Ponkan friuts and found the reduction occurred mainly in the concentration, rather than total content. Additionally, under water stress, the late-stage organic acid concentration in Ponkan friuts was significantly higher than the control group, while the total content was significantly lower. This indicates that the organic acid reduction in the late stage of citrus fruit maturation is due to the increase in the volume, weight, and the resulted water infiltration used to dilute the total concentration [14]. Since the water deficiency will alter the organic acid metabolism, the low total organic acid content might be due to weight loss from water stress.

\subsection{The Influence of Water Stress on Citric Acid Metabolism Related Genes in Ponkan Fruits}

Citric acid is the primary organic acid in the Ponkan fruits. The citric acid content was determined by the synthesis and degradation during the fruit development. Citric acid can be produced by oxaloacetic acid reacting with acetyl-CoA that is catalyzed by Citrate Synthase; it can then be degraded into $\alpha$-ketoglutaric acid and glutamic acid by cis-aconitase and isocitric dehydrogenase. Glutamic acid can form GABA by the catalysis of glutamic acid decarboxylase to enter the GABA pathway. On the other hand, glutamic acid can form glutamine under the catalysis of glutamine synthetase. GABA cycle plays a crucial role in the citric acid degradation [14] [15].

Citrate Synthase (CS) has been reported to be the key enzyme for citric acid synthesis in citrus [16]. However, other research has found no relationship between CS activity and the citric acid level in citrus fruits [17]-[19]. In this investigation, the two CitCSs families increased expression as the time under water stress increased, and having the same trend with the fruit citric acid content. In the maturation stage of the fruits, the relative expressions of CitCS1 and CitCS2 were significantly higher than the control group, which means under water stress, CitCS1 and CitCS2 have a greater impact on citric acid accumulation.

Other researchers have cloned the three family members of the Citrus Aco gene and found that CcAco1 and CcAco2 are induced when the citric acid content begins to fall after reaching its highest peak, and that the expression of CcAco3 is stable throughout [20]. In our research, the expression of CitAco1 was low in the early stage and high in the late stage; the expression of CitAco2 was the lowest in the Aco family, while the expression of CitAco3 was relative stable. The highest expression of CitAco1 was delayed for Ponkan fruits developing under water stress; the highest expression of CitAco2 came earlier, while CitAco3 expression was highest at the early stage of fruit maturation. Under the prolonged water stress, all three were lower than the control group during maturation, showing the influence of water stress on the activities of the three Aco family members.

Among the downstream genes in citric acid degradation, expressions of $\mathrm{CitIDH}$ family members are relatively higher in the middle-late stage of fruit development, indicating that all three genes participated in the Ponkan citric acid degradation. Under $40 \%$ water stress, the relative expression of CitIDH1 was low in the early stage, increased in the middle stage, though significantly lower than the control group, and highest in the maturation stage (significantly higher than the control group). The relative expression of CitIDH2 was always higher than the control group, whose maximum occurred in the maturation stage. The maximal relative expression of $\mathrm{Ci}$ $t I D H 3$ occurred in the middle stage of the fruit development, and was significantly lower in the early stage, and significantly higher in the maturation stage, when compared with the control group. These results indicate that water stress also influences the activities of the three CitIDH gene family members.

Different from the upstream Aco enzyme and the encoding genes, the function of the downstream GABA pathway in the organic acid degradation has just been focused in these few years. Aprile et al. [21] discovered the high expression of GAD and amino acid synthesis related genes of GABA pathway in the sweet citrus fruits using gene chip assays. They thought these might be involved in the citric acid degradation. In our research, we found that both CitGAD4 and CitGAD5 were involved in the citric acid degradation. The expression of CitGAD5 
slightly increased in the late stage of the fruit development, while the expression of CitGAD4 significantly increased in the late stage of fruit development. Water stress of $40 \%$ changed the expression trends of these two genes, leading to the fluctuation of their expressions with the increase of stress duration. However, in the maturation stage, CitGAD4 expression could not be detected, and CitGAD5 showed an increased trend. These results indicate that water stress inhibited the activity of CitGAD4 in the maturation stage, but promoted the activity of CitGAD5 to some extent.

Based on the correlation analysis between the relative expressions of these genes and the citric acid content, we suspect that $40 \%$ water stress promotes the increased expression of CitCS1 and CitCS2, which are involved in the synthesis of citric acid and reduced expression of CitACO1 and CitGAD4, both of which are related to citric acid degradation. The combination of these leads to the significant accumulation of citric acid concentration. Theoretically, low activities of CitACO3, CitIDH1, CitIDH2, CitIDH3 and CitGAD5 benefit from the accumulation of citric acid. In this research, we found their relative expressions were elevated, indicating that organic acid degradation is not controlled by a single gene, but rather by the coordination of a series of genes involved in the degradation. During the long-term water stress, the expression patterns of the related genes changed. In order to explore the expression changes of citric acid metabolism related genes, some stage-specific treatments during the citrus fruits development and maturation should be considered in future research.

\section{Conclusion}

The acid content in Ponkan fruits changes under 40\% water stress, leading to the accumulation of citric acid, the increase in total organic acid, and changes in the expression of citric acid metabolism related genes. The expressions of CitACO1 and CitGAD4 were relatively low, while the expressions of CitCS1 and CitCS2 were relatively high. These discrepancies in gene expression could be one explanation for the accumulation of citric acid under water stress.

\section{References}

[1] Zhou, J.Y. (2010) Molecule Physiological Basis on Genetic Differences of Carotenoid Accumulation and Ethylene Regulation in Citrus. Zhejiang University, Hangzhou.

[2] Deng, S.X. (2009) Physiological Resistance Analysis of Citrus Plants under Deficit Irrigation Conditions. Southwest University, Chongqing.

[3] Yamaki, Y.T. (1989) Organic Acid in the Juice of Citrus Fruits. Journal of Japan Horticultural Science Society, 58, 587-594. http://dx.doi.org/10.2503/jijshs.58.587

[4] Li, Y.Z. (1997) Research Progress on Citrus Fruit Acid Metabolism a Literature Review. Sichuan Fruits, 4, 17-19.

[5] Sun, X.H., Xiong, J.J., Zhu, A.D., Zhang, L., Ma, Q.L., Xu, J., Cheng, Y.J. and Deng, X.X. (2012) Sugars and Organic Acids Changes in Pericarp and Endocarp Tissues of Pumelo Fruit during Postharvest Storage. Scientia Horticulturae, 142, 112-117.

[6] Chen, M., Xie, X.L., Lin, Q., Chen, J.Y., Donald, G., Yin, X.R., Sun, C.D. and Chen, K.S. (2013) Differential Expression of Organic Acid Degradation-Related Genes during Fruit Development of Navel Oranges (Citrus sinensis) in Two Habitats. Plant Molecular Biology Reporter, 31, 1131-1140. http://dx.doi.org/10.1007/s11105-013-0583-2

[7] Tadeo, F.R., Cercós, M., Colmenero-Flores, J.M., Iglesias, D.J., Naranjo, M.A., Rios, G., Carrera, E., Ruiz-Rivero, O., Lliso, I., Morillon, R., Ollitrault, P. and Talon, M. (2008) Molecular Physiology of Development and Quality of Citrus. Advances in Botanical Research, 47, 147-223. http://dx.doi.org/10.1016/S0065-2296(08)00004-9

[8] Anyia, A.O. and Herzog, H. (2004) Water-Use Efficiency, Leaf Area and Leaf Gas Exchange of Cowpeas under MidSeason Drought. European Journal of Agronomy, 20, 327-339. http://dx.doi.org/10.1016/S1161-0301(03)00038-8

[9] Xie, S.X., Liu, Q., Xiong, X.Y., Zhang, Q.M. and Lovatt, C.J. (2011) Influences of Water Stress on Citrus Photosynthesis Characteristic and Cell Ultra-Structure. Acta Agriculturae Universitatis Jiangxiensis, 32, 234-238.

[10] Nie, Q., Lu, X.P., Zhao, X.-L. and Xie, S.X. (2013) ABA Production and Expression Analysis of Its Key Genes in Newhall Navel Orange and Satsuma Mandarin under Water Stress. Journal of Fruit Science, 30, 348-353.

[11] Zhao, X.L., Lu, X.P., Nie, Q., Huang, C.N., Xiao, Y.M. and Xie, S.X. (2013) Effect of Water Stress on Physiological Characteristics, JA Biosynthesis and Correlative Genes Expression in Citrus. Acta Agriculturae Universitatis Jiangxiensis, 35, 530-535.

[12] Wang, H.B., Li, L.G., Chen, X.S., Li, H.F., Yang, J.M., Liu, J.F. and Wang, C. (2010) Flavor Compounds and Flavor Quality of Fruits of Mid-Season Apple Cultivars. Scientia Agricultura Sinica, 43, 2300-2306. 
[13] Luo, A.C., Yang, X.H., Deng, Y.Y., Li, C.F., Xiang, K.S. and Li, D.G. (2003) Organic Acid Concentrations and the Relative Enzymatic Changes during the Development of Citrus Fruits. Scientia Agricultura Sinica, 36, 941-944.

[14] Sadka, A., Artzi, B., Cohen, L., Dahan, E., Hasdai, D., Tagari, E. and Erner, Y. (2000) Arsenite Reduces Acid Content in Citrus Fruit, Inhibits Activity of Citrate Synthase but Induces Its Gene Expression. Journal of the American Society for Horticultural Science, 125, 288-293.

[15] Cercós, M., Soler, G., Iglesias, D.J., Gadea, J., Forment, J. and Talón, M. (2006) Global Analysis of Gene Expression during Development and Ripening of Citrus Fruit Flesh. A Proposed Mechanism for Citric Acid Utilization. Plant Molecular Biology, 62, 513-527. http://dx.doi.org/10.1007/s11103-006-9037-7

[16] Wen, T., Xiong, Q.E., Zeng, W.G. and Liu, Y.P. (2001) Changes of Organic Acid Synthetase Activity during Fruit Development of Navel Orange (Citrus sinesis Osbeck). Acta Horticulturae Sinica, 28, 161-163.

[17] Canel, C., Bailey Serres, J.N. and Roose, M.L. (1996) Molecular Characterization of the Mitochondrial Citrate Synthase Gene of an Acidless Pummelo (Citrus maxima). Plant Molecular Biology, 31, 143-147. http://dx.doi.org/10.1007/BF00020613

[18] Kubo, T., Kihara, T. and Hirabayashi, T. (2002) The Effects of Spraying Lead Arsenate on Citrate Accumulation and the Related Enzyme Activities in the Juice Sacs of Citrus natsudaidai. Journal of the Japanese Society for Horticultural Science, 71, 305-310. http://dx.doi.org/10.2503/jjshs.71.305

[19] Yu, K.Q., Xu, Q., Da, X.L., Guo, F., Ding, Y.D. and Deng, X.X. (2012) Transcriptome Changes during Fruit Development and Ripening of Sweet Orange (Citrus sinensis). BMC Genomics, 13, 10. http://dx.doi.org/10.1186/1471-2164-13-10

[20] Terol, J., Soler, G., Talon, M. and Cercos, M. (2010) The Aconitate Hydratase Family from Citrus. BMC Plant Biology, 10, 222. http://dx.doi.org/10.1186/1471-2229-10-222

[21] Aprile, A., Federici, C., Close, T.J., Bellis, L., Cattivelli, L. and Roose, M.L. (2011) Expression of the H+-ATPase AHA10 Proton Pump Is Associated with Citric Acid Accumulation in Lemon Juice Sac Cells. Functional \& Integrative Genomics, 11, 551-563. http://dx.doi.org/10.1007/s10142-011-0226-3 
Scientific Research Publishing (SCIRP) is one of the largest Open Access journal publishers. It is currently publishing more than 200 open access, online, peer-reviewed journals covering a wide range of academic disciplines. SCIRP serves the worldwide academic communities and contributes to the progress and application of science with its publication.

Other selected journals from SCIRP are listed as below. Submit your manuscript to us via either submit@scirp.org or Online Submission Portal.
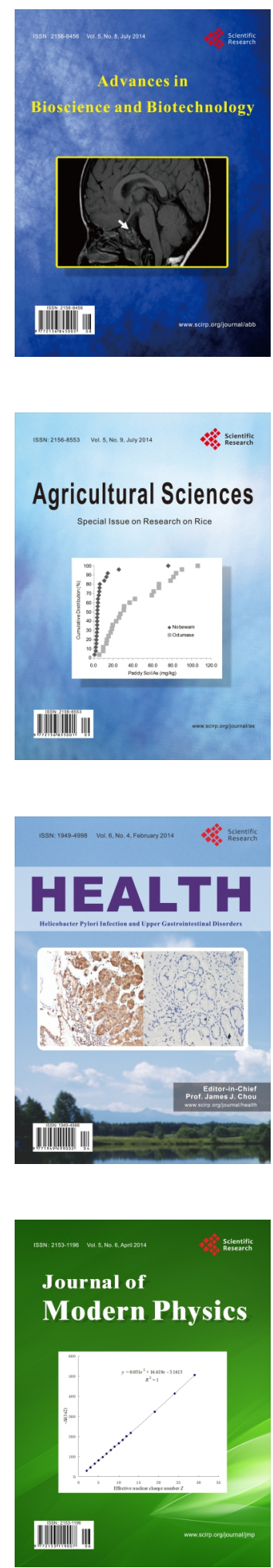
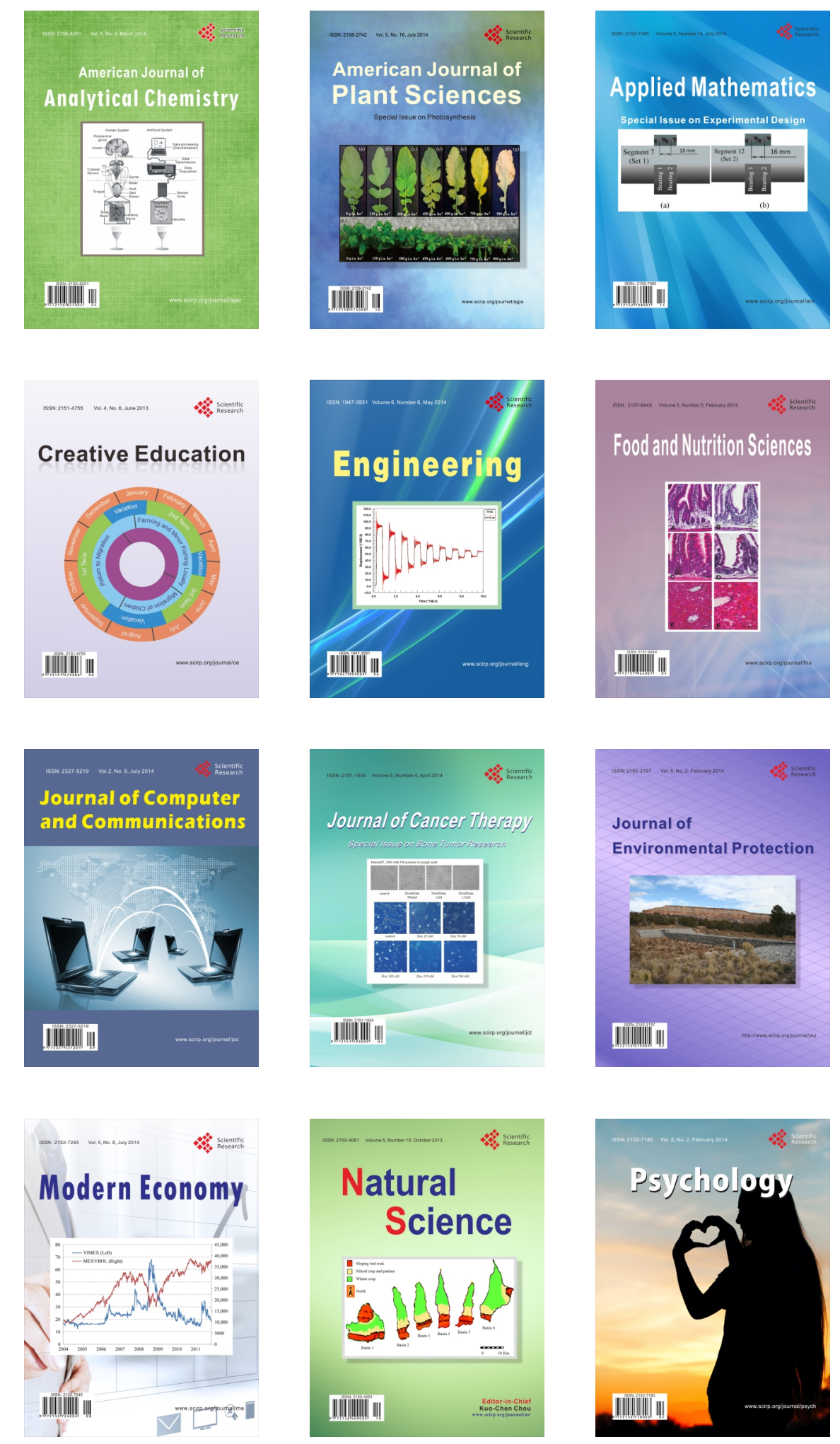